Editors' Note: The AAN's evidence-based guideline for the treatment of parenchymal neurocysticercosis generated several suggestions. WriteClick contributors questioned the guideline's relevance to clinical practice, the studies included and excluded, and the outcomes measured. The authors respond that the guideline's shortcomings reflect the inadequacies found in the literature on neurocysticercosis as a whole.

\section{EVIDENCE-BASED GUIDELINE: TREATMENT OF PARENCHYMAL NEUROCYSTICERCOSIS: REPORT OF THE GUIDELINE DEVELOPMENT SUBCOMMITTEE OF THE AMERICAN ACADEMY OF NEUROLOGY}

Jorge G. Burneo, Alejandro L. Escalaya, London, Canada: The success of a systematic review lies in the adequate selection of the questions that represent the daily problems encountered by treating physicians. NCC is a pleomorphic disease and the clinical behavior of patients harboring one cystic lesion is different from those with multiple intraparenchymal lesions. Confounders can also play an important role in the treatment of NCC including the patient's concomitant use of other medications (e.g., antiepileptic drugs) and stage of the lesions. These factors were not considered in the review by Baird et al. ${ }^{1}$ The authors should have performed systematic reviews in each of the following groups independently: single lesion, multiple lesions, and cysticercotic encephalitis.

Furthermore, the relationship between NCC lesion and seizures is easy to assess when there is a single lesion in a case of new-onset seizures. However, it is more complicated when there are multiple lesions. Even though NCC-related epilepsy is a well-defined syndrome, there is a need to confirm the epileptogenic focus responsible for the seizures in a patient with NCC. Is it located around the lesion or lesions or other epileptogenic lesions? This needs to be ruled out. The authors did not include these types of studies.

Finally, the authors did not define "long-term" seizure control. The selection of 12 months was made without data. A better assessment of long-term seizure control would be more accurate if the analysis was done in those with "resolution" or "inactivation" of the lesions. Unfortunately, those studies are scarce in the medical literature.

Arturo Carpio, Cuenca, Ecuador; Agnes Fleury, Gustavo Vega-Gama, Felipe Garcia-Pedroza, Fernando Rueda-Franco, Mexico City: Baird et al. ${ }^{1}$ demonstrated that there are few evidence-based studies of antihelminthic treatment for NCC. This guideline has some limitations. The authors' procedure was to evaluate treatment based on the reduction of number of cysts. This method is misleading because if only one cyst out of many remains alive after treatment, it could prompt continued or recurrence of symptoms.

The only valid criterion should be the disappearance of all viable parasites. ${ }^{2}$ The authors' recommendation of albendazole treatment to reduce seizure frequency is questionable. The authors studied results that included patients with vesicular (live parasite) infections and patients with colloidal (degenerative/dead parasite) infections to evaluate treatment effect on seizures. It may be inaccurate to combine those studies because-considering the role of inflammation in seizure generation ${ }^{3}$ - parasite phases reveal important differences regarding the intensity of associated inflammatory reaction. ${ }^{4}$ Evaluating treatment using clinical criteria is also problematic because the evolution of NC is unpredictable, with remissions and exacerbations, and overestimation of treatment effect may occur.

This study demonstrates the need for further controlled studies to better ascertain the scope of NCC treatment. Clearly, the most important goal should be prevention.

Alejandra Gonzalez-Duarte, Mexico City: In the guideline by Baird et al., ${ }^{1} 9$ of the studies used in the meta-analysis included patients with single parenchymal cysts, while 4 studies included patients with between 36 and up to 100 cysts. These comparisons are not appropriate, because single cysts are considered benign, whereas multiple cysts can be lethal. In addition, seizure control was used as the only clinical outcome measurement, despite other common manifestations such as encephalopathy, headache, paresis, and dementia. Furthermore, seizures may continue after calcification and so most studies showed a nonsignificant reduction in number of total seizures. Conversely, when the number of active cysts was considered as a surrogate outcome, most studies found a 
significant reduction in active cysts. More importantly, the baffling aspect of NCC is the emergence of severe complications including death while receiving treatment. Steroids are important because it is impossible to foresee the degree of inflammatory response to the parasite destruction. Although there is not enough evidence regarding steroid administration, not administering them while receiving albendazole is hazardous. ${ }^{5}$ Optimal albendazole dose and length of treatment are still unclear. Currently, the only irrefutable recommendation to physicians dealing with NCC is to address each case individually. ${ }^{6,7}$

Nitin K. Sethi, New York: I read with interest the recent AAN evidence-based guideline regarding treatment of parenchymal NCC. ${ }^{1}$ The current practice, especially in patients who harbor a high parenchymal NCC load, is to pretreat the patient with steroids (dexamethasone or prednisone) for 5-7 days before commencing cysticidal therapy with albendazole. The usual recommended dose for albendazole is $15 \mathrm{mg} / \mathrm{kg} /$ day while the duration of anthelmintic therapy varies. The commonly cited reason for pretreatment with steroids is to quell the inflammatory response that may be triggered by the dying larvae on initiation of cysticidal therapy. The inflammatory response is hypothesized to lead to cerebral edema and often seizures. The AAN evidence-based guideline criteria — while helping to stratify some aspects of parenchymal NCC treatment-fails to address important questions regarding steroid use: When should they be started, at what dose, and for how long? A future AAN evidence-based guideline should also address management issues concerning solitary parenchymal NCC granuloma, which may disappear on its own, an entity commonly reported in the Indian subcontinent. ${ }^{8}$

Author Response: Ruth Ann Baird, Indianapolis; Sam Wiebe, Calgary, Canada; Joseph R. Zunt, Seattle; John J. Halperin, Summit, NJ; Karen L. Roos, Indianapolis: We thank the authors for their comments on this guideline. ${ }^{1}$ As stated previously, AAN guidelines require Class I, Class II, or Class III evidence, as defined by the AAN classification of evidence scheme provided in the publication, to support recommendations. Our systematic literature search revealed 610 potentially informative abstracts, review of which identified 123 articles that we then analyzed in detail. We based recommendations on the literature's very limited, high-level evidence. We certainly agree that more high-level studies addressing the many important but as yet unanswered clinical questions would be extremely helpful. A goal of evidence-based literature reviews and guideline development is to identify gaps in the literature relating to important clinical questions, as indicated in our suggestions for future research.
Following are our responses to the authors' comments:

1. Suggestion: Pretreatment with steroids and assessment of endpoints other than seizures or imaging findings. Our response: These suggestions are not supported by any high-level evidence and therefore would not meet the required criteria for an AAN guideline recommendation.

2. Suggestion: Use of disappearance of all viable parasites as the only valid criterion by which to evaluate treatment.

Our response: Given the limitations of the studies analyzed, we were unable to determine whether all viable parasites were killed; detailed information regarding cyst stage and response of cysts to treatment was not provided by most studies, and no study reported elimination of all viable cysts as an endpoint. Despite this limitation, as seizure frequency was significantly reduced in patients who received albendazole, if bias were present in our analysis due to remaining viable cysts, this would underestimate rather than overestimate the effect of treatment on seizure frequency.

3. Suggestion: Performance of systematic reviews in each of the following groups independently: single lesion, multiple lesions, cysticercotic encephalitis. Our response: Although we agree that the proposed studies would be helpful, they have not been done. Our guideline incorporated the best available data that addressed the most relevant questions. We refer the authors to our recommendations for future research provided at the end of the guideline, particularly this: "Neurocysticercosis can be intraventricular or intraocular or can involve the subarachnoid space."

For more information regarding formulation of AAN guidelines and assessment of quality of evidence, we refer readers to the article by Gronseth and French, "Invited article: Practice parameters and technology assessments: What they are, what they are not, and why you should care."

(C) 2013 American Academy of Neurology

1. Baird R, Wiebe S, Zunt J, et al. Evidence-based guideline: treatment of parenchymal neurocysticercosis: report of the Guideline Development Subcommittee of the American Academy of Neurology. Neurology 2013;80:1424-1429.

2. Carpio A, Fleury A, Hauser WA. Neurocysticercosis: five new things. Neurol Clin Pract 2013;3:118-125.

3. Singh G, Burneo JG, Sander JW. From seizures to epilepsy and its substrates: neurocysticercosis. Epilepsia 2013;54:783-792.

4. Vezzani E, Balosso S, Ravizza T. Inflammation and epilepsy. Handb Clin Neurol 2012;107:163-175.

5. Ramos-Zúñiga R, Pérez-Gómez HR, Jáuregui-Huerta F, et al. Incidental consequences of antihelmintic treatment in the central nervous system. World Neurosurg 2013;79:149-153.

6. Sotelo J. Clinical manifestations, diagnosis and treatment of neurocysticercosis. Curr Neurol Neurosci Rep 2011;11: 529-535. 
7. Gonzalez I, Garcia HH. Current status and future perspectives on the medical treatment of neurocysticercosis. Pathog Glob Health 2012;106:305-309.

8. Kishore D, Misra S. Short course of oral prednisolone on disappearance of lesion and seizure recurrence in patients of solitary cysticercal granuloma with single small enhancing
CT lesion: an open label randomized prospective study. J Assoc Physicians India 2007;55:419-424.

9. Gronseth G, French J. Invited article: practice parameters and technology assessments: what they are, what they are not, and why you should care. Neurology 2008;71:16391643.

\section{Neurology ${ }^{\circledR}$ WriteClick: Join the Debate!}

The editors encourage comments about recent articles through WriteClick:

Go to www.neurology.org and click on the "WriteClick" tab at the top of the page. Responses will be posted within 72 hours of submission.

Before using WriteClick, remember the following:

- WriteClick is restricted to comments about studies published in Neurology within the last eight weeks

- Read previously posted comments; redundant comments will not be posted

- Your submission must be 200 words or less and have a maximum of five references; reference one must be the article on which you are commenting

- You can include a maximum of five authors (including yourself)

\section{Save These Dates for AAN CME Opportunities!}

Mark these dates on your calendar for exciting continuing education opportunities, where you can catch up on the latest neurology information.

\section{Regional Conference}

- October 25-27, 2013, Las Vegas, Nevada, Encore at Wynn Hotel

\section{AAN Annual Meeting}

- April 26-May 3, 2014, Philadelphia, Pennsylvania, Pennsylvania Convention Center

\section{Target Your Job Search}

Your goal is precise, your time is precious. So give it your best shot. The AAN's Neurology Career Center is the largest neurology-specific job site tailored to in-demand neurology professionals like you.

Visit www.aan.com/careers and create your free profile today. 


\section{Neurology}

Evidence-based guideline: Treatment of parenchymal neurocysticercosis: Report of the Guideline Development Subcommittee of the American Academy of Neurology Jorge G. Burneo, Arturo Carpio, Alejandra Gonzalez-Duarte, et al. Neurology 2013;81;1474-1476

DOI 10.1212/WNL.0b013e3182a7afaf

This information is current as of October 14, 2013

\section{Updated Information \&} Services

References

Permissions \& Licensing

Reprints including high resolution figures, can be found at: http://n.neurology.org/content/81/16/1474.full

This article cites 9 articles, 3 of which you can access for free at: http://n.neurology.org/content/81/16/1474.full\#ref-list-1

Information about reproducing this article in parts (figures,tables) or in its entirety can be found online at:

http://www.neurology.org/about/about_the_journal\#permissions

Information about ordering reprints can be found online: http://n.neurology.org/subscribers/advertise

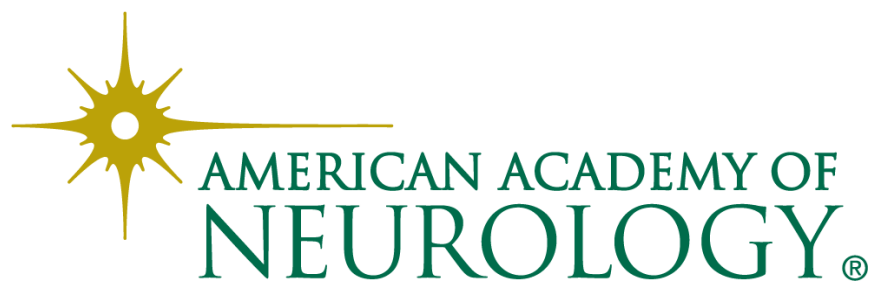

